\title{
Socio-Spatial Analysis of Amman Axial
}

\author{
Nabeel Yusuf Alkurdi \\ Associate Professor, Department of Architecture - School of Engineering, The University of Jordan.
}

\begin{abstract}
Studying the relationship between the spatial organization of the urban fabric and social interaction is of great importance as it helps to develop a preventive strategy for the future in avoiding the numerous effects of losing social vitality from important parts of the city.

This research aims to explore the dialectic relation between syntactic properties of space and the social dynamics in the city. To reach the goal, a structure of social integration contents in Amman city, is traced on two levels: the global city scale and for local districts. An axial map of "13661" lines is prepared for Amman by the researchers, and the conceptions of Space Syntax theory and the earlier and more general Graph Theory are utilized as evaluation tools for the social vitality of the axial spaces. The "integration" values are calculated using UCL Depth map Software. The outcome graphs of the UCL Depth map provide two important results; first, on the global city scale, the existence of a literally biased social vitality of urban spaces, since the axial lines with relatively high integration values are almost all located in western Amman; while the vast majority of eastern Amman axial lines has lower integration values. The other result is on the micro scale, the absence of a social-based clear definition of an urban space in the city of Amman.
\end{abstract}

Keywords: Amman, Axial map, Social integration, Space syntax, UCL Depth map.

\section{INTRODUCTION}

A growing contrast in the architectural, social and cultural identity is notable between older and newer parts of the rapidly expanding urban content in the major Middle Eastern cities. Some researchers believe that two or more completely different lifestyles evolve in the same city, while Middle Eastern cities have grown dramatically over the past decade. By 2020, 90 percent of the populations of major countries such as Bahrain, Kuwait, Lebanon, Qatar, Oman and Saudi Arabia are expected to be urban-dwelling. [1].

The case of Amman provides an interesting example of a Middle Eastern capital city that in the last few decades has experienced significant changes in social structure. A theoretical model was constructed by two urban geographers studying these changes; the model is characterized by dual nodes, the old city and the new, with a transitional commercial zone between them. Nineteenth and early 20th century lower-class suburban housing and slums are clustered around the remnants of the medieval city while older upperclass housing is clustered around the transition zone, flanked on either side by industrial areas, including rail facilities. Modern middle and upper-class residences have developed beyond the far end of the new city, away from the decaying medina. This model is generally accepted by scholars. [2].

The newly emerging planned and modern/ Westernised urban environments seemingly created a split city, where different urban spaces represented binary oppositions - the 'old city', stood for 'tradition' and 'local' life, while the new public buildings, commercial centers, and residential neighborhoods created an urban iconography of imported 'modernity'. In reality cities were never totally segmented. [3] . The concept of the unchanging and chaotic medina is being gradually abandoned and substituted by a more organic model. [4] . Urbanization in the Middle East fit easily with neither dependency theory nor decolonization models, perspectives that did not consider the great diversity of Middle Eastern states and political economies. [5] .

Amman has been subjected to accelerated processes of change on different scales, creating a novel physical and sociocultural environment which bears little affinity with its older counterpart [6].

The problem of un-balanced social growth in Amman was explored by Ham \& Greenway; they considered the explosive growth in the last fifty years mostly concentrated in West Amman "Residents talk openly of two parts, although in truth there are many. Eastern Amman (which includes Downtown) is home to the urbanized poor: it is conservative, more Islamic in its sympathies, and has vast Palestinian refugee camps on its fringe. Western Amman is a world apart, with leafy residential districts, trendy cafes and bars, impressive art galleries, and young men and women walking openly arm in arm" [7] .

Many other researchers signified the problem with different methodologies. In this research, unlike most of the previous literature, the social dynamics of the city are to be graphically represented and analyzed.

\section{THEORY OF SPACE SYNTAX}

Space syntax is a set of techniques for analyzing spatial configuration of all kinds; especially where spatial configuration seems to be a significant aspect of human functions and activities as it is in a building and cities. [8] .

Originally conceived by Hillier and his colleagues as a tool to help architects simulate the likely effects of their design, it has since grown to become a tool used all around the world in a variety of research areas and design applications. It has been 
extensively applied in the fields of architecture, urban design, planning, transportation and interior design.

Space syntax is not a traffic model, it is an urban design model modelling aspects of urban form, and it is a model for researching the effectiveness of urban space (seen as an extended integral system) as the materials real-world context and career of urban activity [9].

\section{II.I UNIT OF SPACE SYNTAX}

Every point in the space has one and two dimensional aspects, the one dimensional is called axiality; the other is called convexity.

\section{II.I.I AXIALITY}

Axial lines are defined as the longest visibility lines covering entirely open spaces of an urban environment. The least number of axial lines constitutes what is often called an axial map. The axial map, a key of space syntax representation [8], is actually a skeleton representation of urban environments [9].

This map is a basis of layout analysis. It represents how far observers can have an uninterrupted impression of visibility and permeability as they move about town and look at a distance towards the various directions. The map draws the fewest and longest lines of uninterrupted permeability deriving the map, which are necessary to cover the public open space of an area [10]. When all the relations between spaces in the entire system are taken into consideration; this map represents the spatial structure globally, and locally, when only the relation between the single axial space and the other attached axial spaces is taken into consideration, see Fig.1
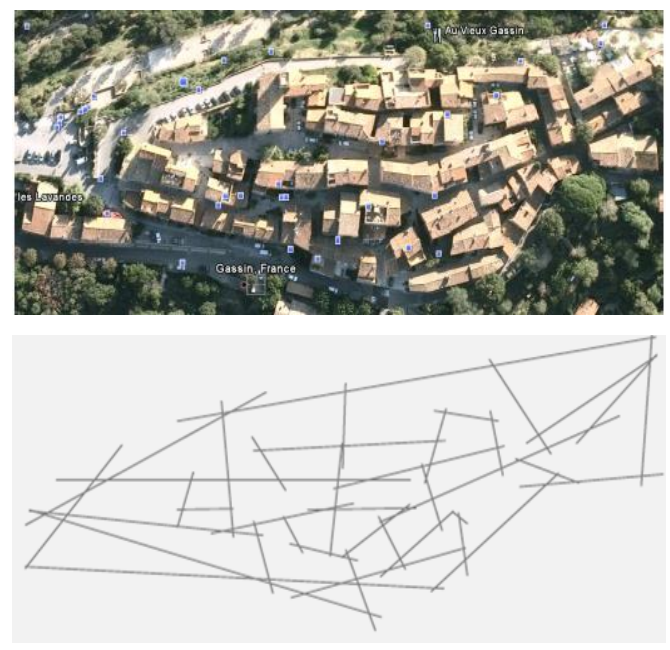

Fig. 1: Converting urban tissue to an axial map [11]

\section{II.I.II CONVEXITY}

A convex space is defined as "a space that will not contain concave parts" [8]. It is an area outlined by a border of straight lines, any two points in this convex space can be joined by a straight line which does not go outside the space. A convex map consists of the largest and fattest convex spaces that cover the area. The convex space offers the most localized perspective because any selected point taken within it appears visible and directly accessible to all other points within that same space. Convex spaces are used when studying interaction [10], see Fig .2.
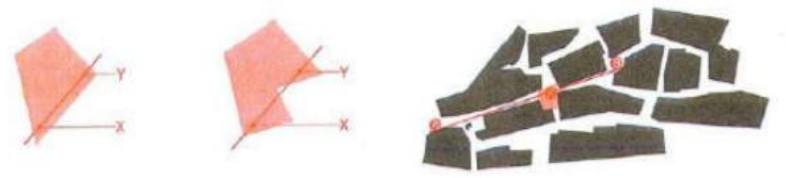

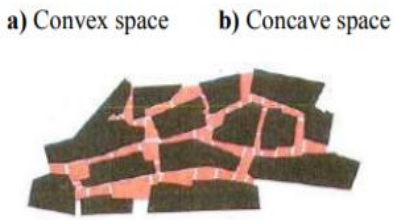

d) Convex map

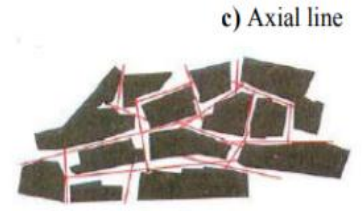

e) Axial map
Fig.2: Space syntax tools [10]

\section{II.II SYNTACTIC PROPERTIES OF AXIAL MAPS}

There are important spatial property parameters in the Axial Map graph. First of all 'connectivity' is defined as the number of nodes directly linked to each individual node in the connectivity graph. The second parameter 'control value' expresses the degree of choice each node represents for its directly linked nodes. The third parameter, 'integration' is a value which indicates the degree to which a node is more integrated or segregated from a system [11].

These parameters can be used to describe both local and global properties of a spatial configuration in the sense of integration or segregation. Mean Depth and integration are clarified in the following sections.

\section{II.III MEAN DEAPTH}

The concept of depth is introduced in the sense that the axial or convex segments are either many steps that are deep from buildings or from the carrier, or building, or few steps that are shallow from buildings or the carrier. Relations of depth necessarily involve the notion of asymmetry, since spaces can only be deep from other spaces if they are necessary to pass through intervening spaces to arrive at them [12]. Jiang

Mean depth can be expressed visually and can be calculated analytically, to calculate the mean depth of any point, by assigning a depth value to each space according to how many spaces are away from the original space, then we sum these values and divide it by the number of spaces in the system less one (the original space) [Ibid]

$$
(\mathrm{MD})=\sum \mathrm{D} / \mathrm{k}-1
$$

MD is mean depth of the original space

$\mathrm{D}$ is the depth of other spaces to it (number of axial steps from the original space)

$\mathrm{k}$ is the number of axial spaces in the system. 


\section{II.IV INTEGRATION PROPERTY}

Integration is the fewer intervening lines which need to be passed through to go from a line to every other line. It is in contrast with mean depth, obtained by dividing the total depth by $\mathrm{k}$, the number of spaces in the system, the most integrated lines means minimum depth. In other words, integration $\alpha$ $1 /$ mean Depth so the more segregated spaces means higher depth [13], see Fig. 3
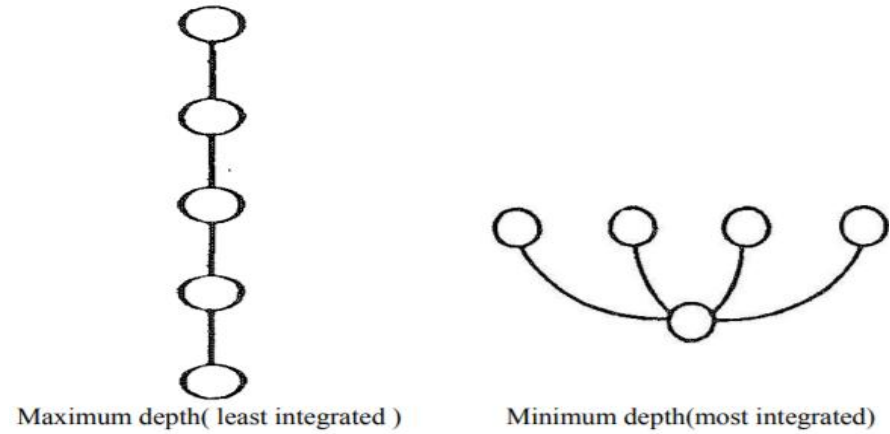

Minimum depth(most integrated)

Fig.3 Relation between integration and depth [12]

\section{METHOD}

In this stage, Axial graphs are prepared for sixteen different districts in Amman, searching the least and most sensible axial spaces, the graph is drawn based on GAM maps for the city, see Fig.4.

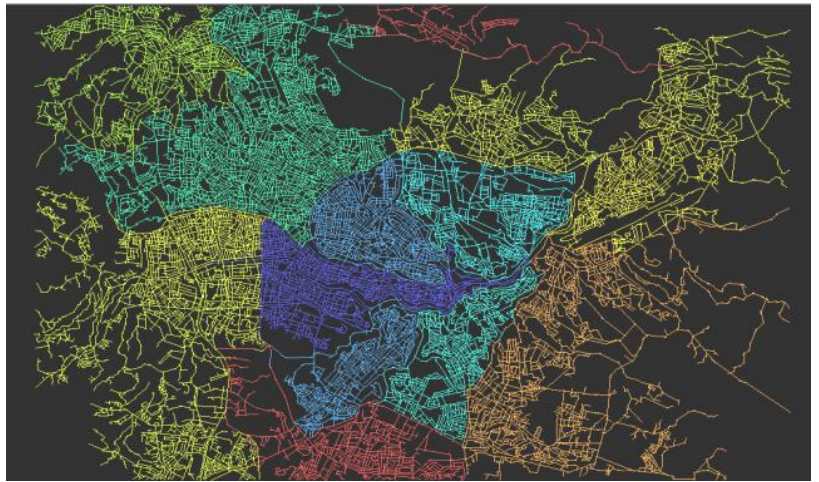

Fig.4 Calculation of Amman districts in a Global axial map (By Researcher)

The data base is processed in two parallel approaches:

1. Measurement of global syntactic parameters by joining the districts maps, removing duplicate lines, converting the graph to axial map definition, and finally running axial graph analysis using UCL Depth map software.

Note: the axial graph analysis is performed twice, first using radius (6); where integration values are calculated for each axial line just on the nearest 6 steps to the line, and the second performed analysis is using radius ( $\mathrm{n}$ ); where the integration value is calculated for each axial space based on the maximum possible number of steps to reach the farthest axial space in the system.

Table 1: Global \& Local Integration values for different districts taken from the UCL Depthmap software [14]

\begin{tabular}{|c|c|c|c|c|c|c|c|c|c|}
\hline \multirow{2}{*}{ District } & \multicolumn{3}{|c|}{ Global Integration $(\mathrm{HH})$} & \multicolumn{3}{|c|}{ Integration (Radius 6) } & \multicolumn{3}{|c|}{ Local Integration $(\mathrm{HH})$} \\
\hline & Min & Average & Max & Min & Average & Max & Min & Average & Max \\
\hline 0: Al Medina & 0.36123177 & 0.529940222 & 0.59917986 & 0.33964917 & 1.168704987 & 1.6229486 & 0.24911399 & 0.625691766 & 1.0540147 \\
\hline 1: Zahran & 0.42821127 & 0.582019973 & 0.69330615 & 0.33964917 & 1.373081456 & 2.323364 & 0.4394969 & 0.914282728 & 1.5057044 \\
\hline 2: Abdali & 0.4607392 & 0.573618477 & 0.68307912 & 0.39030147 & 1.369041823 & 2.0217469 & 0.41571775 & 1.000718477 & 1.7643142 \\
\hline 3: Badr & 0.39862442 & 0.512985456 & 0.63797569 & 0.42470458 & 1.199823382 & 2.0396531 & 0.42116278 & 0.897176981 & 1.632423 \\
\hline 4: Basman & 0.3186729 & 0.50129471 & 0.62885886 & 0.34478623 & 1.251204016 & 1.976234 & 0.31693122 & 0.701663632 & 0.97339284 \\
\hline 5: Al-Yarmouk & 0.35999155 & 0.440128514 & 0.55105191 & 0.41469529 & 1.099770364 & 1.7619004 & 0.4313066 & 0.751281088 & 1.3112713 \\
\hline 6: Ras AL-Ein & 0.38530082 & 0.459075595 & 0.58262885 & 0.366666667 & 1.143803804 & 1.7173077 & 0.34850776 & 0.648725608 & 1.0592915 \\
\hline 7: Tla'a Al-Ali & 0.3613089 & 0.525432892 & 0.68229294 & 0.42807257 & 1.289362195 & 1.9498311 & 0.35064468 & 0.682848134 & 1.0196137 \\
\hline 8: Al-Jubeha & 0.3316958 & 0.489582666 & 0.64575005 & 0.33964917 & 1.232115478 & 2.0809195 & 0.419204 & 0.720341195 & 1.1343124 \\
\hline 9: $\quad$ Sweleh & 0.25419393 & 0.421471762 & 0.58016163 & 0.33964917 & 1.084339559 & 1.9356974 & 0.28478229 & 0.554833778 & 0.87771064 \\
\hline 10:Wadi Al-Sair & 0.19510548 & 0.457180697 & 0.67235619 & 0.33964917 & 1.124481993 & 2.1499825 & 0.1764798 & 0.452505859 & 0.71227682 \\
\hline 11: Tareq & 0.22088559 & 0.394490895 & 0.60735631 & 0.33964917 & 1.064978205 & 1.8132311 & 0.19361973 & 0.341952309 & 0.46044651 \\
\hline 12: Marka & 0.29506239 & 0.413772822 & 0.5457654 & 0.33964917 & 1.142120789 & 1.8136183 & 0.31695879 & 0.671786706 & 0.31695879 \\
\hline 13: Al-Nasr & 0.20422371 & 0.37011799 & 0.52436614 & 0.33964917 & 1.007701654 & 1.7629164 & 0.19367036 & 0.505636265 & 0.76561552 \\
\hline 14:Al-Qwesmih & 0.1943263 & 0.370193418 & 0.48997021 & 0.33964917 & 1.055229479 & 1.7108792 & 0.20662436 & 0.566560158 & 0.86729074 \\
\hline 15: Um Qasr & 0.31785312 & 0.462298254 & 0.5966993 & 0.33964917 & 1.206539385 & 1.9207473 & 0.25623077 & 0.758664953 & 1.2784338 \\
\hline 16:Shafa Badran & 0.25126395 & 0.372578493 & 0.47307599 & 0.34478623 & 0.938542572 & 1.401652 & 0.19246078 & 0.387621233 & 0.61632133 \\
\hline
\end{tabular}

2. Measurement of the local syntactic parameters: by running an axial graph analysis for each single district after converting it to an independent axial map. As a result for this step, local integration cores are recognized for each district. Table 1 is prepared by the researcher based on a summary of the results of data processing. 
International Journal of Engineering Research and Technology. ISSN 0974-3154, Volume 13, Number 8 (2020), pp. 1901-1908

(C) International Research Publication House. https://dx.doi.org/10.37624/IJERT/13.8.2020.1901-1908

\section{III.1 ANALYSIS AND INTERPRETATION DATA}

Graphical \& numerical comparative analysis is held for the data sheet following two directions, Fig. 5:

Vertical Analysis: comparing global and local syntactic properties of different districts to each other, the aim of this comparison is shown in Fig. 5.

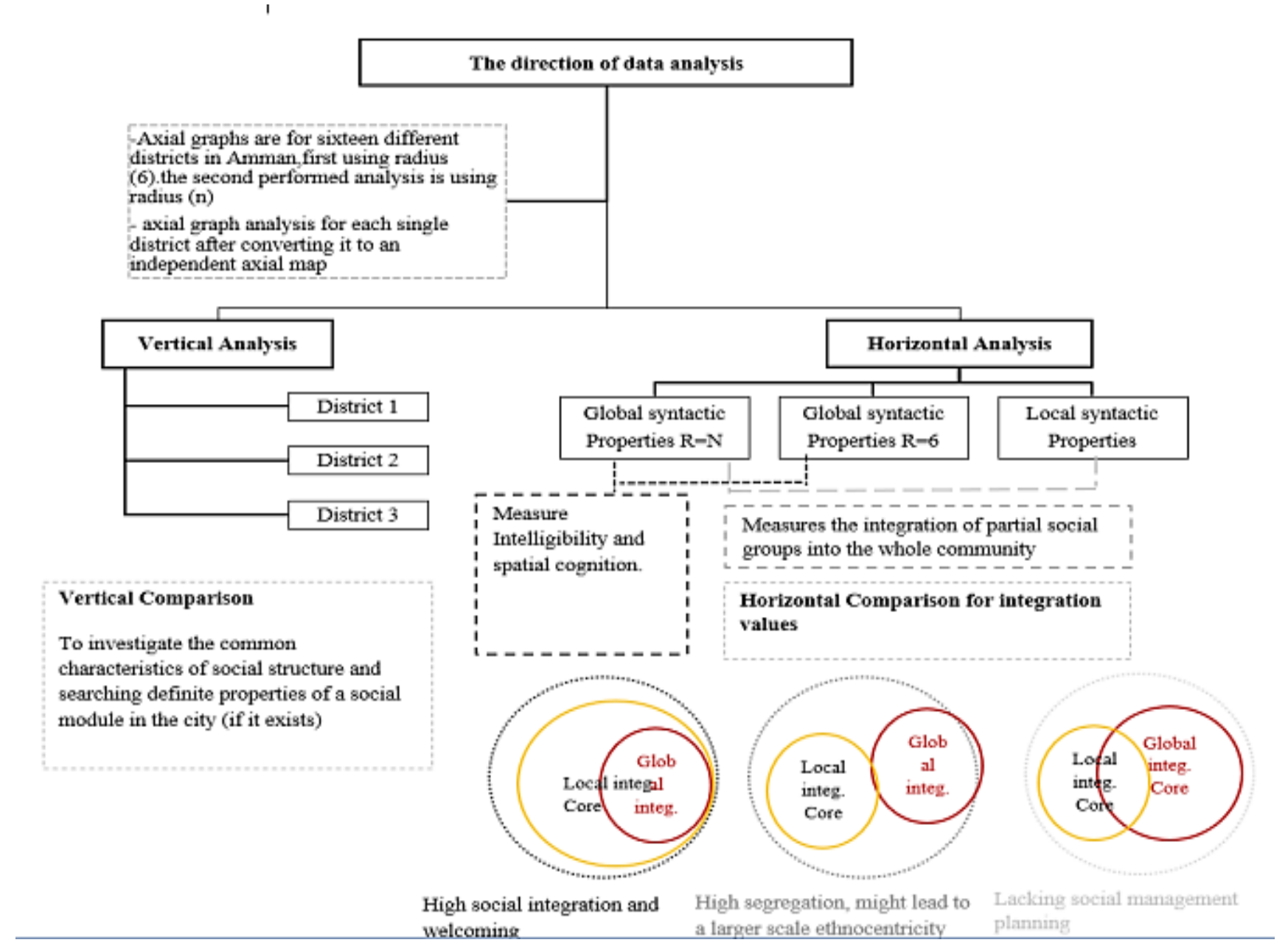

Fig. 5 Strategic data analysis of table 1(By Researcher)

\section{RESULT}

Considering the global scale of Amman city, the software analysis shows the existence of four topologically distinguishable categories of social spaces.

$>$ The first order social spaces (social hub of the city):

The following fig. 6 and table 2 taken from UCL depth map software indicated that the global syntactic properties of Amman axial spaces, unlike their local design features, push towards establishing a global social hub in Western Amman, but the problem of miss-coordination with local design features made these spaces mostly vehicular spaces that lack even the minimum qualification to receive a city scale size of social interaction, these streets were designed to be the traffic heart of the city.

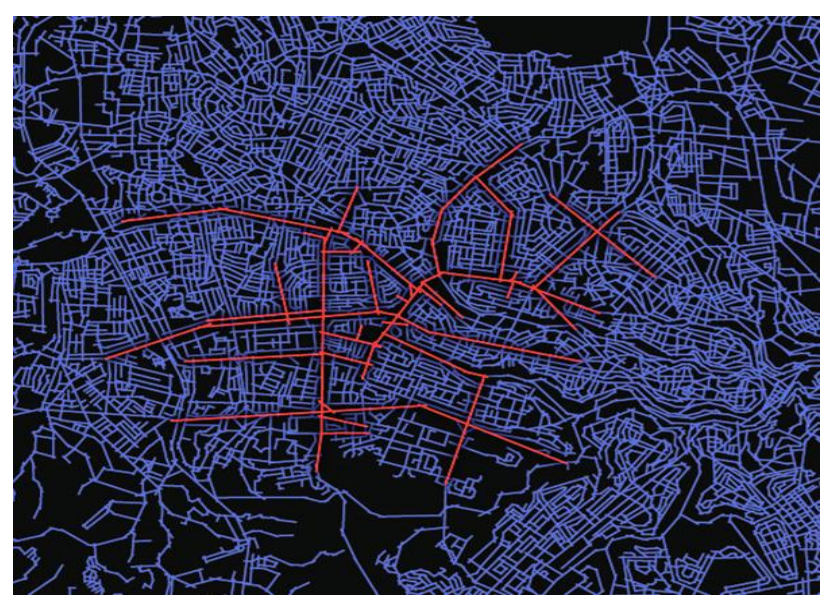

Fig. 6 First order social spaces (social hub of the city) [UCL Depthmap Analysis] 
International Journal of Engineering Research and Technology. ISSN 0974-3154, Volume 13, Number 8 (2020), pp. 1901-1908

(C) International Research Publication House. https://dx.doi.org/10.37624/IJERT/13.8.2020.1901-1908

Table.2: Names and number of segments contained in axial spaces with Integration $\mathrm{HH}>0.65$

intrg $\mathrm{HH}>0.65$
King Faisal bin Abd Al Aziz
Makka AL Mukarrama
Zahran
Queen Zein Al Sharaf
Al Medina Al Munawara
Mohammad Ali Janah
Al Kanadi Street
Prince Shaker bin Zayd

intrg $\mathrm{HH}>0.65$

Makka AL Mukarrama

Zahran

Queen Zein Al Sharaf

Al Medina Al Munawara

Al Kanadi Street

Prince Shaker bin Zayd

number of Segments
involved
3 Segments
4 segments
5 segments
2 segments
1 segment
2 segments
1 segment
3 segments

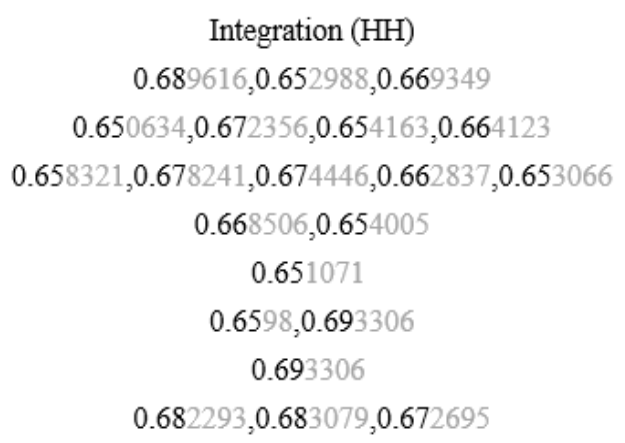

$>$ second order socially integrated spaces (transitional spaces):

It is worth mentioning that the al-Madina district, although being the historical core and containing richly diverse cultural heritage, is defined as a transitional space in terms of its global integration values, so it is necessary to consider its

relation to other districts if any enterprise is to be done for revitalization or restoration of the traditional social rule of this core. See Fig. 7.
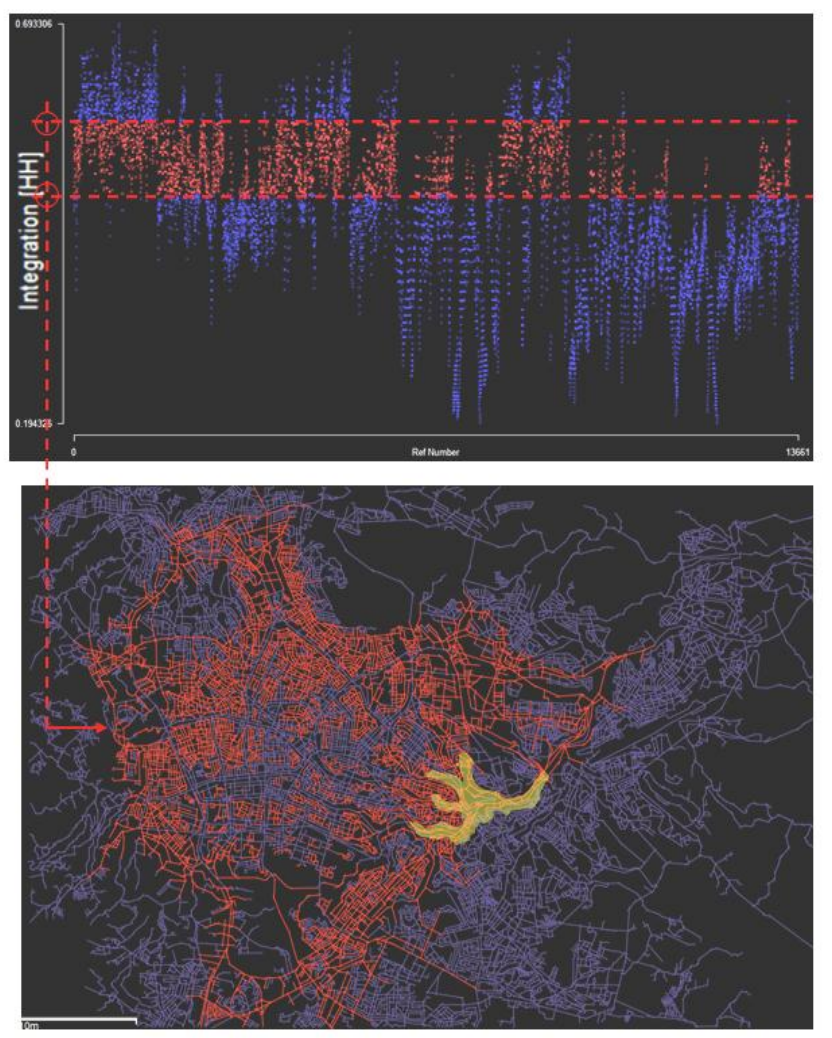

Fig.7: Second order socially integrated spaces (transitional spaces)

$>$ Third order (relatively segregated axial spaces):

Axial lines of the 3rd order space have low values of global integration, this fact defines what is -or what potentially can be in future - social segregation cores in the city, most of these spaces are concentrated in East Amman. Actually this does not mean that these spaces are badly designed or deteriorating, but the problem lays in their relation to other districts of the city and the unplanned permeability and accessibility to and from these spaces. See Fig. 8
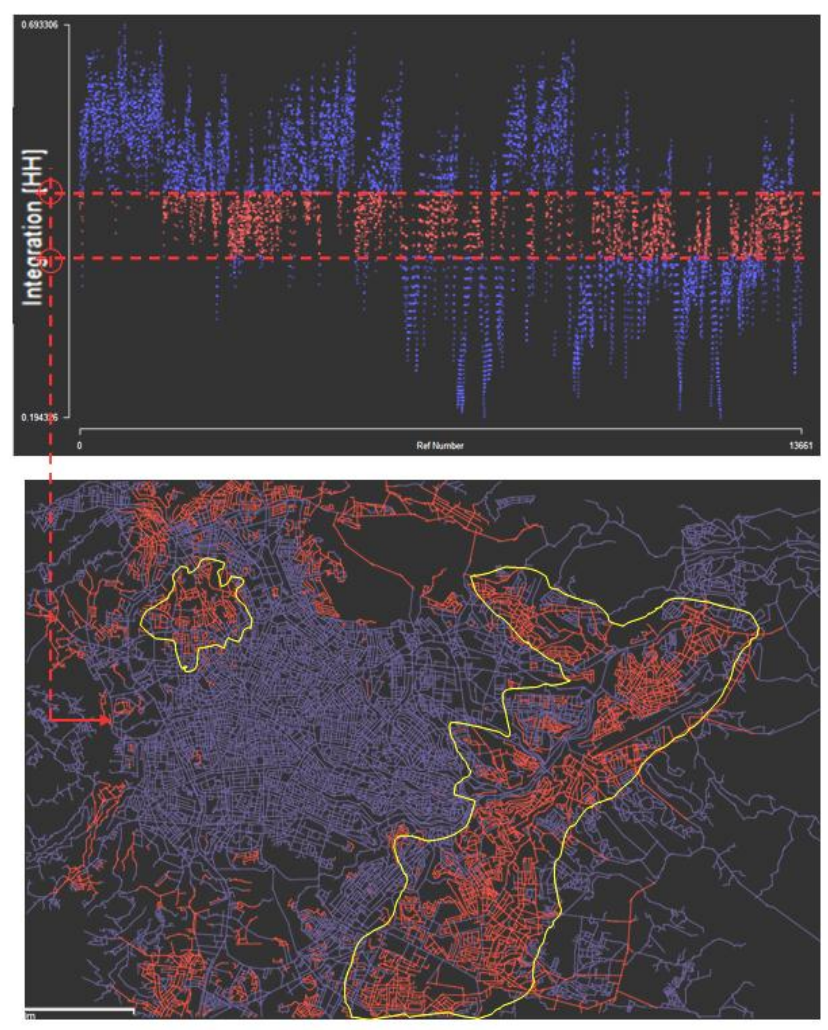

Fig.8: Third order (relatively segregated axial spaces)

$>$ - Under development axial spaces:

Axial spaces with very low values of global integration are usually located in low density regions that have not reached their mature social pattern yet; these spaces are the most responsive for modification and interventions, the planning interventions in this stage determine if the next stage will be 
International Journal of Engineering Research and Technology. ISSN 0974-3154, Volume 13, Number 8 (2020), pp. 1901-1908

(C) International Research Publication House. https://dx.doi.org/10.37624/IJERT/13.8.2020.1901-1908

an integration or a segregation core according to the way the new spaces are connected with older ones. See Fig.9
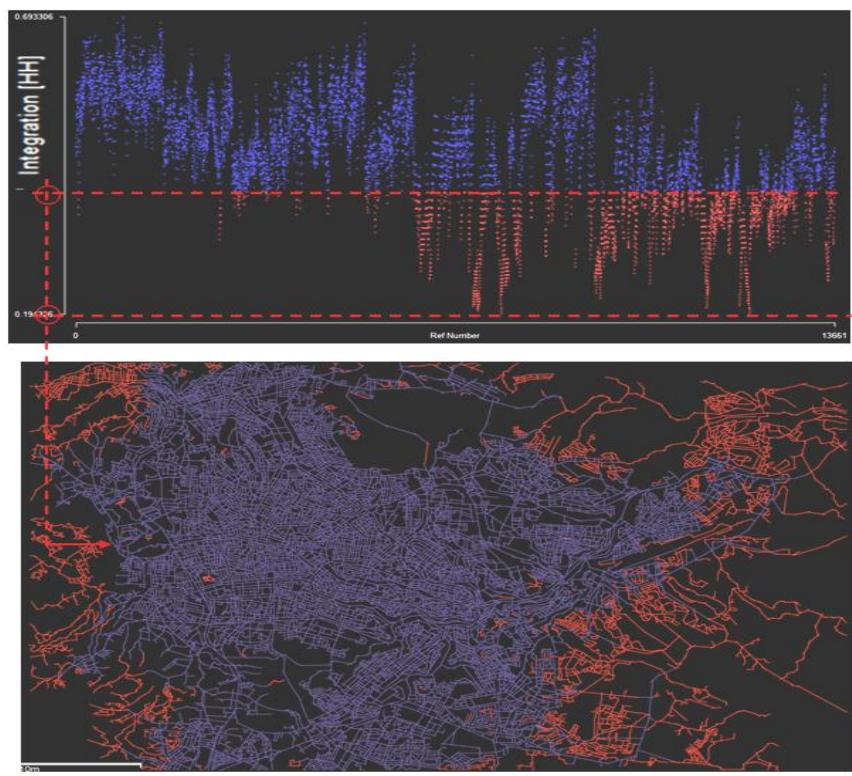

Fig.9: under development axial spaces.

This is a numerical comparison for different districts, while a more cognitive sight for the social structure of these districts is shown in the following pages, the most striking note is the very weak overlap between local and global integration cores, the meaning of this was previously illustrated in Fig. 10, 11,12 .
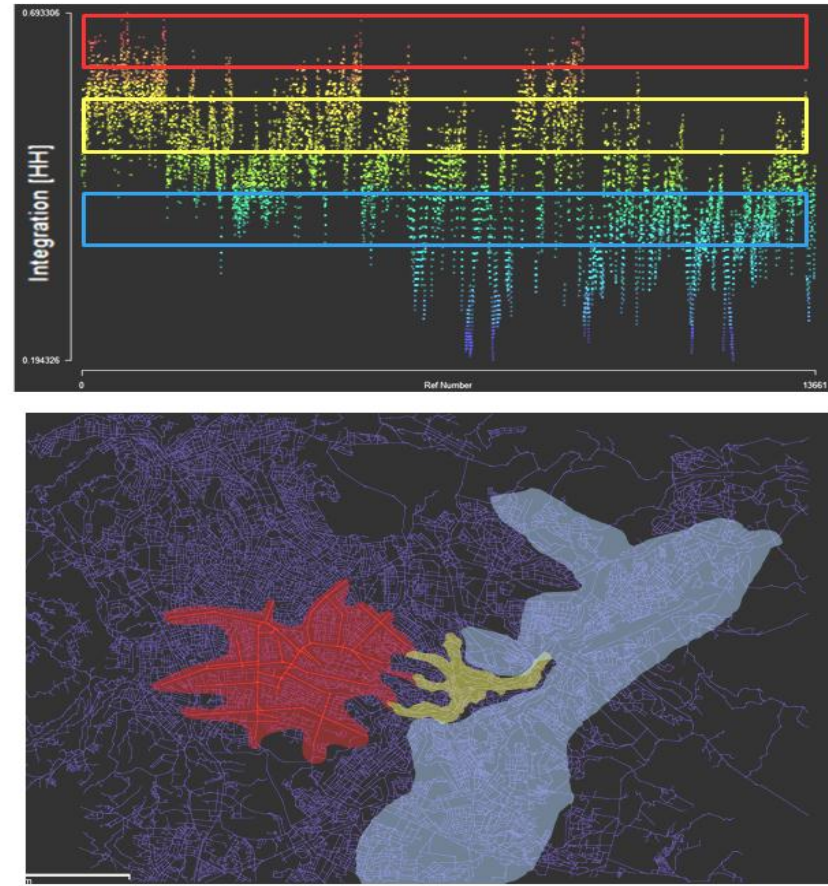

Fig.10: The social configuration on the global scale of Amman (Red= High integration, Yellow= transitional space, Blue $=$ low integration (potential segregation)) [researchers using UCL depthmap]

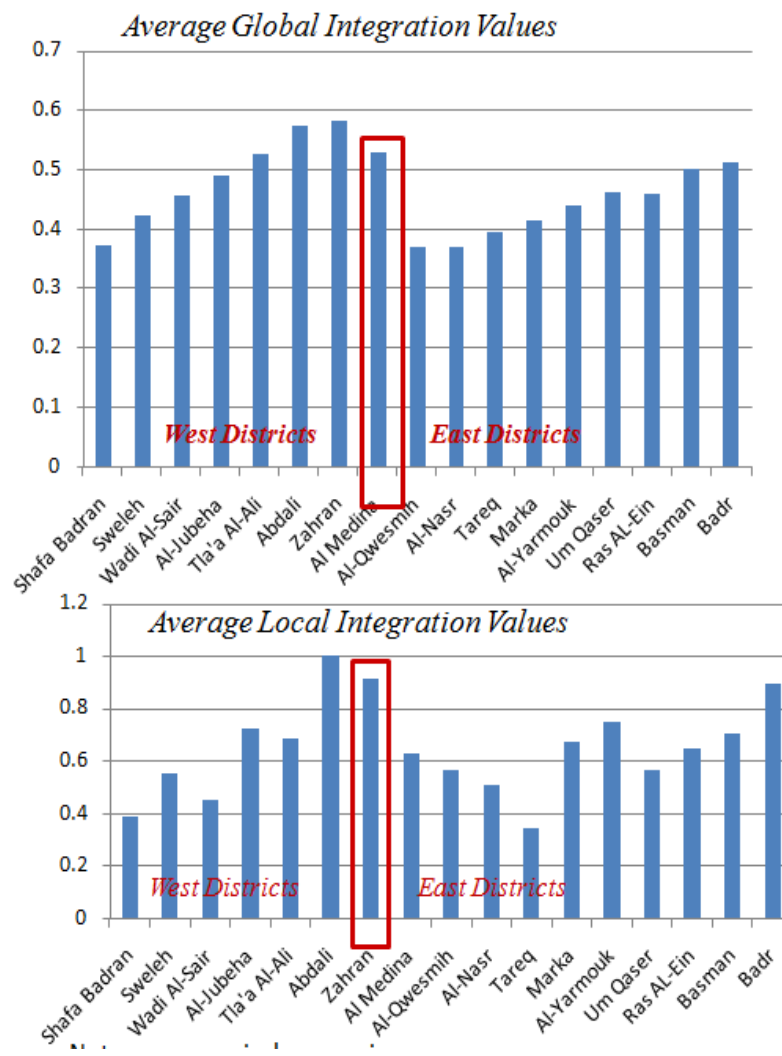

Global Integration Ranges (Max-Min)
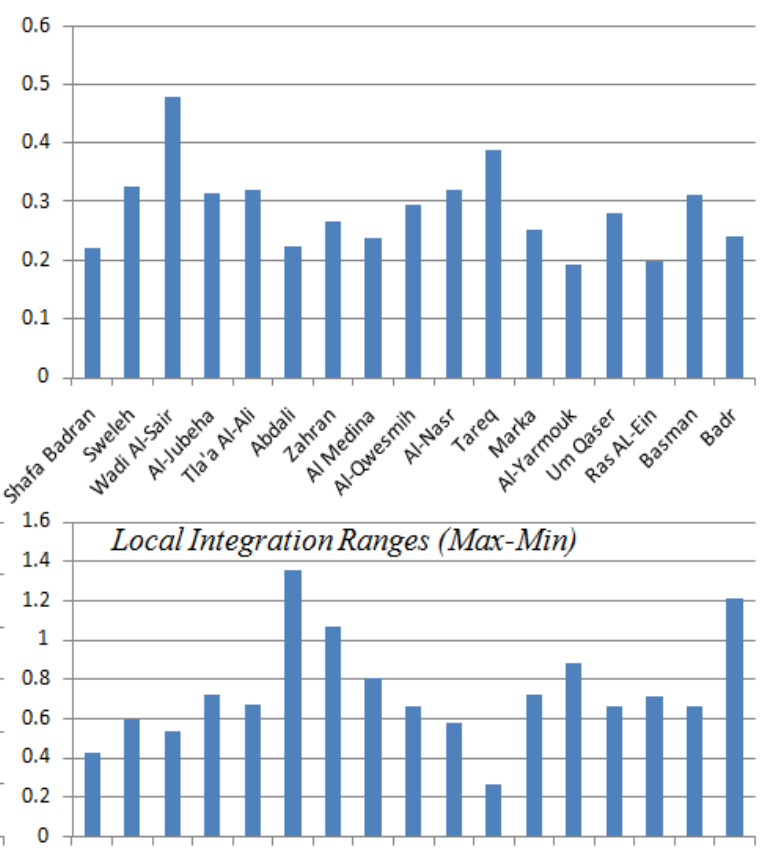

$x^{2}$

Fig.11: Vertical comparison for integration values of different districts in table 1 

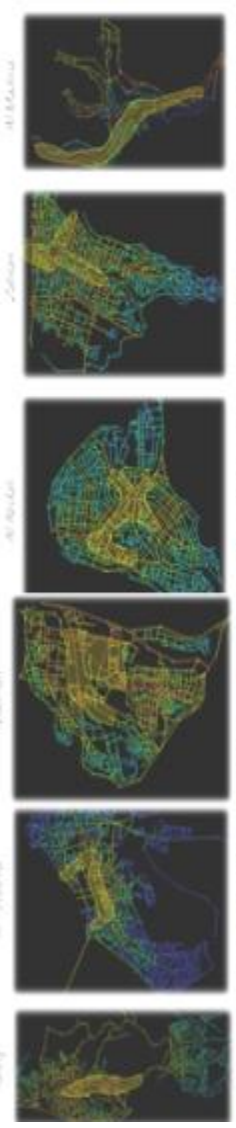
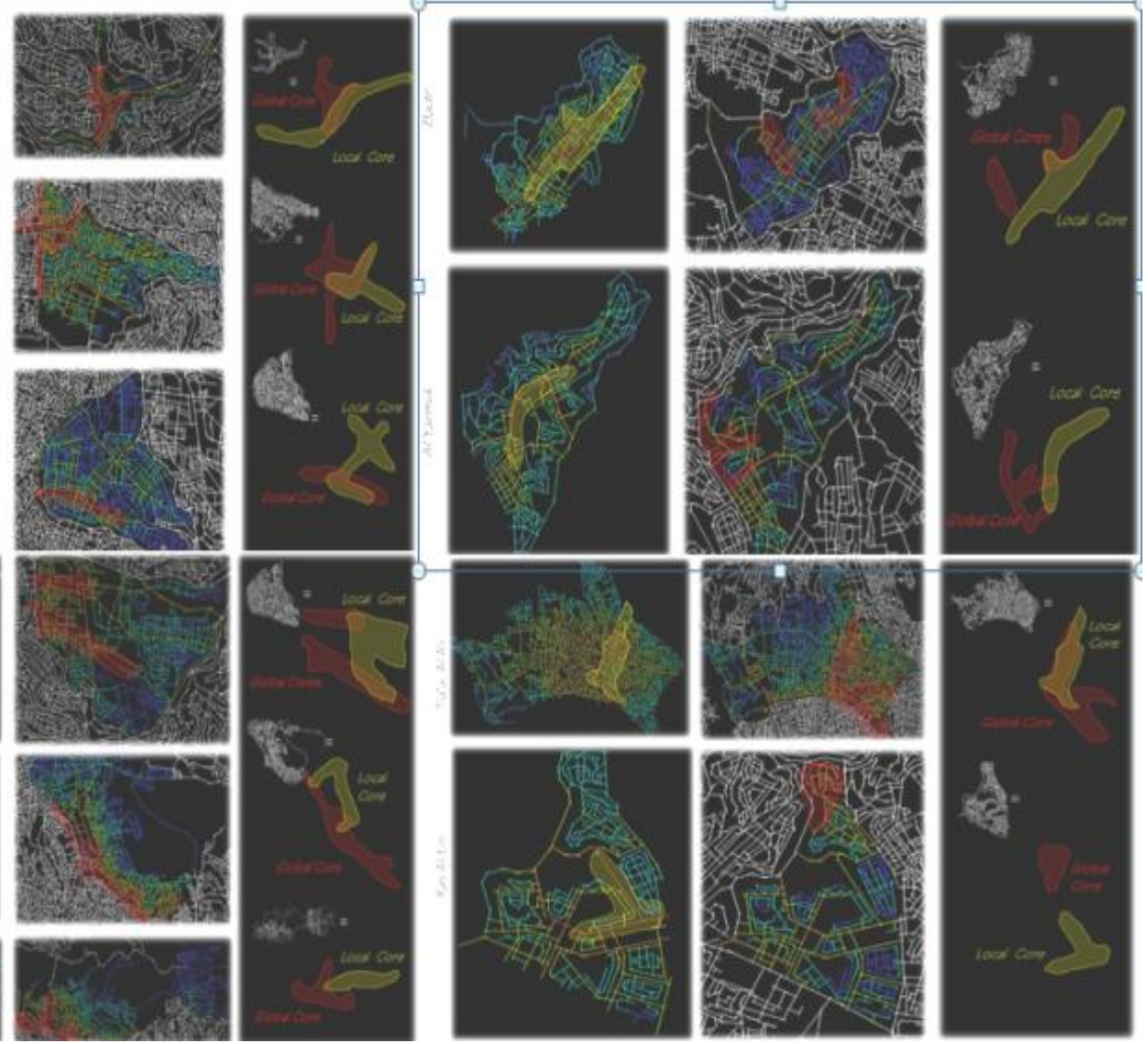

Fig. 12 Samples of Horizontal comparison for integration values of Amman districts in Table (1)

\section{CONCLUSION}

Districts of Western Amman are found to have higher average integration values than Eastern Amman, while the large variation in ranges of integration, allows us to firmly conclude the absence of a clear socially defined module in the Amman Master Plan and that the management of social content is hardly considered in the administrative subdivision criteria of the planning committee.

The plotted patterns of overlap between local and global integration cores in the districts also vary, since some districts like Zahran show a relatively acceptable overlap, while others like Al-Qwesmih and Marka signify a dangerous tendency towards segregation.

The axial map as a whole failed the intelligibility test although some segments may pass it independently; this failure interprets the fact that the historical core in Al-Madina, although being locally vital and attractive due to its human friendly design features, on the global scale it is more defined as a thoroughfare rather than a core attraction.

Finally, this research is not trying to find a solution for unbalanced socio-spatial structures which already exist, but states that for better future addressing of urban sustainability criteria in the under-development zones, it is highly recommended to give more attention to the part-whole relation in future plans and consider the global context of spaces in coordination with their local design features.

\section{REFERENCES}

[1] Bates D., Peoples and Cultures of the Middle East., New Jersey,USA: Prentice Hall, 2001.

[2] Stern S. and Soffer A., "The Port City: A Subgroup of the Middle Eastern City Model," Ekistics, pp. 102-110, 1986.

[3] Yakobi Y. and Shechter R. , Rethinking cities in the Middle East: Political economy, planning, and the lived space. The Journal of Architecture. 2005, pp. 499-515

[4] Gutiérrez C. G. , Secondary Mosques in Madinat Qurtuba : Islamization and Suburban Development through Minor Religious Spaces. Papers from the Institute of Archaeology. 2015, 25: 2, pp. 1-18, DOI: http:// dx.doi.org/10.5334/pia.479

[5] Silver H., Divided Cities in the Middle East. City \& Community, December, 2010, pp. 345-357.

[6] Fethi, I. and Mahadin, K., "Villa architecture in Amman: The current spectrum of styles", in J. Hannoyer and S. Shami (eds.), Amman the City and its Society, Beyrouth, Cermoc, 1996.

[7] Ham, A., \& Greenway, P. Jordan (5th ed.). Victoria, Australia: Lonely Planet, 2003.

[8] Tarabieh K., Nassar K. and Abdelrahman M., "Statics of space syntax: Analysis ofdaylighting," Frontiers of 
International Journal of Engineering Research and Technology. ISSN 0974-3154, Volume 13, Number 8 (2020), pp. 1901-1908

(C) International Research Publication House. https://dx.doi.org/10.37624/IJERT/13.8.2020.1901-1908

Architectural Research, pp. 311-318, 13 May 2019.

[9] Jessop M., "The Inhibition of Geographical Information in Digital Humanities Scholarship," Literary and Linguistic Computing, p. 39-50, 20 Novamber 2007.

[10] Hiller B. and Hanson J., The Social Logic of Space, Cambridge: Cambridge University Press, 1984.

[11] Hiller B., "Space is The Machine.," University Press, Cambridge, pp. 160-168, 1996.

[12] Jiang B., "The Image of the City: From the Medial Axes to the AxialLines.," 2009.

[13] Hiller B., "Basis Of Space Syntax Technique," in BILL HILLIER MAPPING METHOD, London, 1984.

[14] Amman Vision Document, a discussion paper. Greater Amman Municipality, Master Plan Initiative,. www.ammancity.gov.jo/english/master/m1.asp (2007) 